Universidad de Lima

Facultad de Derecho

Carrera de Derecho

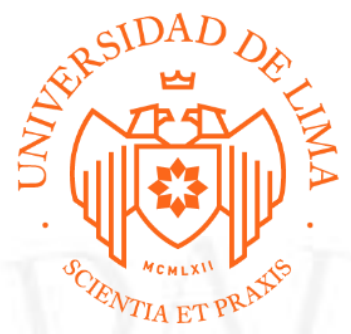

\title{
CIVIL: "VIOLENCIA FAMILIAR" Y PENAL: "VIOLACIÓN DE MENOR DE EDAD"
}

Trabajo de suficiencia profesional para optar el Título Profesional de Abogada

Mariana Milagros Aguirre Alvarado

Código 20131540

Lima - Perú

2019 


\title{
CIVIL: "VIOLENCIA FAMILIAR"
}

Materia: Derecho Civil (Familia)

$\mathrm{N}^{\circ}$ de Expediente: $\mathrm{N}^{\circ} 00096-2009$

\author{
PENAL: "VIOLACIÓN DE MENOR DE EDAD" \\ Materia: Derecho Penal \\ $\mathrm{N}^{\circ}$ de Expediente: $\mathrm{N}^{\circ} 1743-2005$ \\ RESUMEN
}

El expediente versa sobre la denuncia interpuesta por A. A. A., en contra de B. B. B. B. por la supuesta violación sexual a su menor hija, la menor de 13 años de edad de iniciales C. C. C. 